\title{
Zur Kenntniss der Gattung Caloenas Reitt.
}

\author{
Von Dr. K. Escherich in München.
}

Das Genus Caloenas wurde von Edm. Reitter (Deutsch. Entom. Ztschrft. 89. pag. 34) auf ein aus dem Araxesthal stammendes Exemplar gegründet, das sich hauptsächlich durch die Bild ung d e r K la u en von den anderen Meloiden wesentlich unterscheidet. Die Klauen sind nämlich n i ch t g e s palten, sonderninnen in der Mitte tief eingeschnitten, dort einen grossen dornförmigen Zahn bildend. Eine solche Bildung findet sich meines Wissens nur noch bei der californischen Gattung Tegrodera Le Conte, von der L a c o rd a ire in seinen „Genera des coleoptères" (T. V. Pl. 60) die Klauen abbildet.

Die Enddornen der Hinterschienen sind e infach, schlank, beide von gleicher Stärke und in der Länge nur wenig verschieden; darin stimmt Caloenas mit der Gattung Zonabris Hrld. überein. Auch in Bezug auf die Fühler zeigt sie Anklang an letztere Gattung, indem diese nämlich gegen die Spitze an Stärke etwas zunehmen. Der Besitz eines Stirnauges, ferner die Form des Thorax, sowie überhaupt der ganze Habitus documentirt zweifellos eine verwandtschaftliche Beziehung zur Gattung Zonabris, so dass ich überrascht bin, dass R e it t e r Caloenas mit Oenas in Vergleich zieht und nicht mit Zonabris. Wahrscheinlich dachte genannter Autor dabei an Oenas coccineus Mén., der aber, wie ich nachwies, gar nicht zu Oenas, sondern zu Lytta Fbr. gehört!

Bis jetzt war von Caloenas nur eine Art bekannt, C. pulcher Reitt,, der folgendermassen diagnosticirt ist (Deutsch. Ent. Zeitschrft. 89. pag. 35): „Niger, nitidus, subglaber, elytris subparallelis, brunneo-rufis, macula magna basali communi fasciaque sat lata apicali nigris. - Lo n g.: 14-15 mm."

Durch die Güte des Herrn L. Gan $g$ lb a u e r bin ich in die Lage versetzt, dieser einen Art noch $z$ wei weitere höchst a us g e z e i c h n e te S p e c i es hinzufügen zu können, die sich im k. k. Hofmuseum in Wien befinden. 
Caloenas ornaticollis m. n. sp.

Niger, nitidus, thorace elytrisque brunneo-testaceis, illo parvis maculis rotundis duabus nigris ornato, his fascia apicali nigra ornatis; fronte inter oculos macula oblonga rubra ornata; capite longitudine paulo longiore, temporibus longis, rotundatis, sparsim punctatis; thorace subquadrato, lateribus angulisque rotundatis, basi recta, marginata, disco valde nitido, sparsim, ut in temporibus et vertice, punctaia. Scutello parvo, glabro, transversim impresso. Elytris longis, rugoso-coriaceis, lateribus parallelis, venis tribus elevatis ornatis. Antennis brevibus, thoracis basin vix attingentibus, apicem versus vix incrassatis, articulo secundo parvo, tertio longo, secundo triplo longiore.

L o n g.: 15-16 mm. - Patria: P e r s i a.

Flügeldecken und Halsschild röthlich braungelb, letzterer stark glänzend, jederseits der Mitte mit einer kleinen, runden schwarzen Makel versehen; seine Scheibe eben, manchmal mit einer Spur einer erhabenen Längslinie; die Seiten des Halsschildes schön gerundet, die grösste Breite ein wenig vor der Mitte liegend; Basis fein gerandet. Flügeldecken zusammen bedeutend breiter als der Halsschild, sehr lang, mässig gewölbt, mit ziemlich parallelen Seiten, an der Spitze einzeln abgerundet. Die schwarze Apicalbinde vorn eingebuchtet. Fühler kurz, die Basis des Halsschildes kaum erreichend, gegen die Spitze zu ein wenig stärker werdend.

4 Exemplare im Wiener Hofmuseum, mit den Angaben: Persia, Strauss 1891.

\section{Caloenas Semenowi m. n. sp.}

Statura praecedenti similis, differt ab hoc thorace nigro, elytris unicoloribus brunneo-testaceis.

L o n g. : $15 \mathrm{~mm}$. - Patria: Pers i a.

Diese Art unterscheidet sich von ornaticollis hauptsächlich durch die ganz verschiedene Färbung, indem bei ihr der Halsschild einfärbig schwarz und die Flügeldecken einfärbig braun sind. Das Scutellum ist an der Spitze ebenfalls braun.

Durch die Färbung nähert sie sich ein wenig dem pulcher Reitt.; von diesem unterscheidet sich Semenowi ausser durch die eintärbig braunen Flügeldecken, durch den glänzenden, glatten, äusserst fein und zerstreut punkt i r t e n Halsschild und die längere, schlankere Figur so charak- 
teristisch, dass eine Verwechslung der beiden Arten ausgeschlossen ist.

$10^{7} \mathrm{im}$ Wiener Hofmuseum. - P e r si a, Strauss 1891.

Ich erlaube mir diese Art Herrn A. Semenow in Petersburg zu widmen, der die Kenntniss der schwierigen Familie der Meloiden, besonders der transkaspischen Fauna durch eine Anzahl äusserst gediegener kritischer Arbeiten wesentlich gefördert hat.

\section{Synopsis.}

1. Capite thoraceque nigris.

a) Capite thoraceque valde nitidis, glabris perparce p unct at is, elytris unicoloribus, brunneis.

Semenowi n. sp.

b) Capite thoraceque parum nitidis, fortiter punctatis, elytris macula magna basali communi fasciaque apicali nigris.

pulcher Reittr.

2. Thorace brunneo-testaceo, maculis nigris duabus ornatis, elytris fascia apicali nigra.

ornaticollis n. sp.

\section{I'T E R A T U R.}

Rhynchota.

Melichar L. Cicadinen von Mitteleuropa. (Berlin, Verlag von Felix

L. D a mes. 1896, pag. 1 -364, mit 12 Tafeln. - Preis: 20 Mk.)

Das schön ausgestattete Werk in gr. $8^{0}$, das der Autor seinem Vater zum 80. Geburtstage widmete, enthält ein Vorwort; die darauf folgende Einleitung, eine kurze historische Uebersicht der Autoren, die sich bisher eingehender mit diesen Insecten befasst haben, dann ein Literaturverzeichniss; die Stellung der Cicadinen im zoologischen Systeme, die Erklärungen über die äussere Anatomie der Cieadinen; über das Vorkommen, Sammeln und Präpariren derselben; endlich im Haupttheile: die Darstellung der mitteleuropäischen Cicadinen-Fauna. Den eingehenden klaren Beschreibungen geht stets ein dichotomischer Schlüssel voraus, die ersteren mit sehr vollständigen Citaten aus allen bisherigen wichtigeren Cicadinen-Arbeiten und zwar abweichend von der bisherigen Gepflogenheit am Schlusse der Einzelbeschreibungen, was zur Uebersichtlichkeit aller Theile wesentlich beiträgt. Die Geschlechter werden überall sehr sorgfältig unterschieden; auch fehlt es nicht an neuen Arten. Das stattliche Werk zeigt von grossem Fleisse und gewissenhafter Verarbeitung des einschlägigen Materials, und es wäre sehr zu wünschen, dass auf Grund dieses ausgezeichneten Werkes recht vicle Freunde und Anhänger sich der hochinteressanten Insectengruppe der Cicadinen zuwenden wollten; allen Hemipterologen sei Melieh ar's Cicadinen-Werk auf's Beste empfohlen.

E. Reitter.

Wiener Entemologische Zeitung, XV. Jahrg., III. Heft (31. März 1896). 


\section{$2 \mathrm{BHL}$ Biodiversity Heritage Library}

Escherich, Karl. 1896. "Zur Kenntniss der Gattung Caloenas REITT." Wiener entomologische Zeitung 15, 121-123. https://doi.org/10.5962/bhl.part.13870.

View This Item Online: https://www.biodiversitylibrary.org/item/43774

DOI: https://doi.org/10.5962/bhl.part.13870

Permalink: https://www.biodiversitylibrary.org/partpdf/13870

\section{Holding Institution}

Smithsonian Libraries

\section{Sponsored by}

Smithsonian

\section{Copyright \& Reuse}

Copyright Status: NOT_IN_COPYRIGHT

This document was created from content at the Biodiversity Heritage Library, the world's largest open access digital library for biodiversity literature and archives. Visit BHL at https://www.biodiversitylibrary.org. 